\title{
Emergency endoscopic negative pressure therapy of a long oesophageal perforation in eosinophilic esophagitis with a single-lumen nasogastric tube-like open-pore film drain
}

After a bolus event with recurrent hematemesis, a 46-year-old patient complained of severe thoracic pain. Computed tomography revealed extensive paraesophageal mediastinal emphysema over

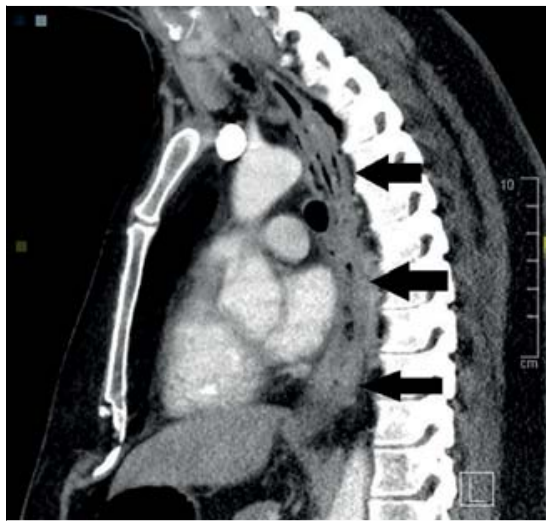

- Fig. 1 Initial computed tomography shows the mediastinal emphysema (arrows) 3 hours after the spontaneous perforation event. Source: Department of Diagnostic and Interventional Radiology of Marienkrankenhaus Hamburg. the entire length of the esophagus ( Fig. 1, $>$ Video 1).

During endoscopy with $\mathrm{CO}_{2}$-inflation, an $8-\mathrm{cm}$ transmural distal perforation (from $31-39 \mathrm{~cm}$ ) was found with gaping wound edges. An extraluminal wound cavity could not be passed. Within 6 hours after the perforation event, immediately after the endoscopic diagnosis, intraluminal endoscopic negative pressure therapy was established with continuous negative pressure of $-125 \mathrm{mmHg}$ (ACTIV.A.C., $\mathrm{KCl}$ USA Inc., San Antonio, Texas, USA) [1,2]. For the initial emergency treatment, we used a single-lumen open-pore film drain with a $25-\mathrm{cm}$ drainage element (Suprasorb CNP drainage film; Lohmann \& Rauscher, Rengsdorf, Germany) ( Fig.2). The long drainage element covered the perforation defect completely [3].

The single-lumen open-pore film drain is like a nasogastric tube (NGT), but with the additional benefit that suction can be applied. The thin diameter of $6 \mathrm{~mm}$ allows transnasal insertion.

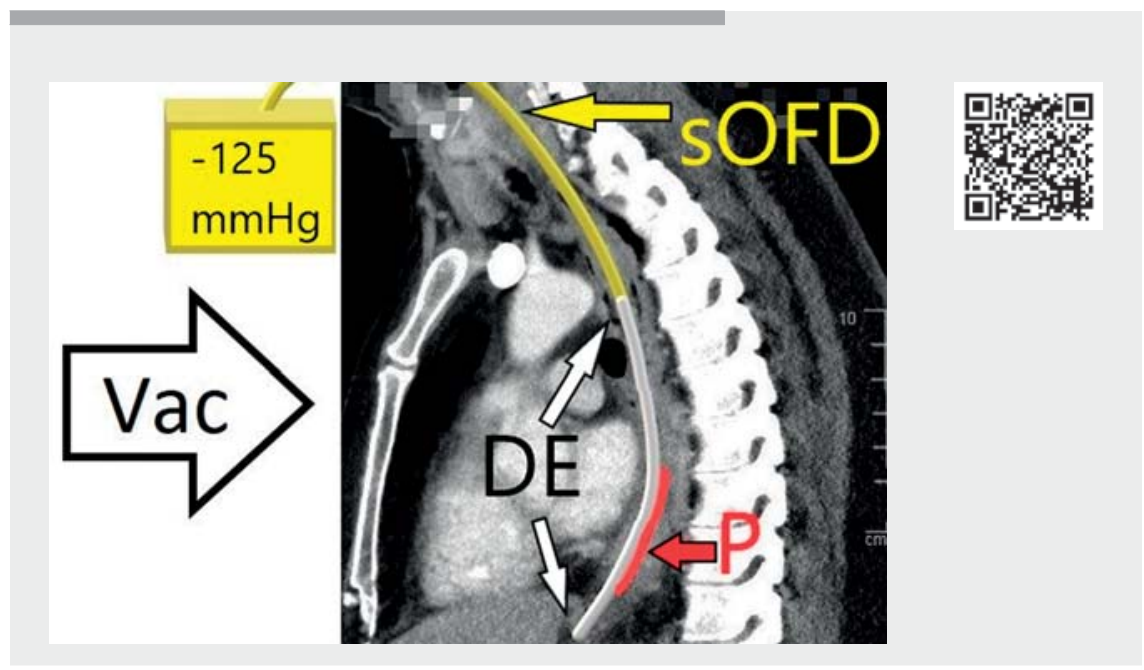

$\checkmark$ Video 1 Emergency intraluminal endoscopic negative pressure therapy with a nasogastric tube-like single-lumen open-pore film drain for spontaneous esophagus perforation in eosinophilic esophagitis. Source for radiological images: Department of Diagnostic and Interventional Radiology of Marienkrankenhaus Hamburg.

After 36 hours, the drain was replaced with a single-lumen open-pore polyurethane foam drain with a $15-\mathrm{cm}$ drainage element ( $\mathbf{F i g . 2}$ ) $[1,2,4]$. The perforation defect had already been taped and was still present as a broad ulceration ( $\triangleright$ Fig. 3).

After a total of 4 days, intraluminal endoscopic negative pressure therapy ended with stable wound conditions ( $\triangleright$ Fig.4, $\checkmark$ Video 1$)$. The patient was discharged

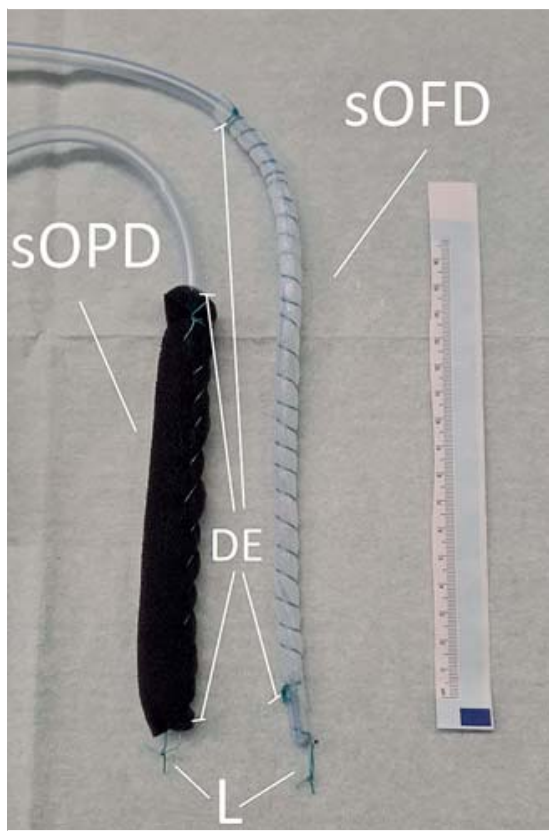

- Fig. 2 Two types of open-pore drains with long drainage elements were used to cover the long perforation defect for intraluminal endoscopic negative pressure therapy with $125 \mathrm{mmHg}$ of negative pressure. A single-lumen open-pore film drain and a polyurethane foam drain were used. Initial emergency endoscopic negative pressure therapy was started with the nasogastric tube (NGT)-like single-lumen open-pore film drain. The drain had a diameter of only $6 \mathrm{~mm}$. It was easily inserted like an NGT through the nose. SOFD, single-lumen open-pore film drain; sOPD, single-lumen open-pore polyurethane foam drain; DE, drainage element; L, loop. 


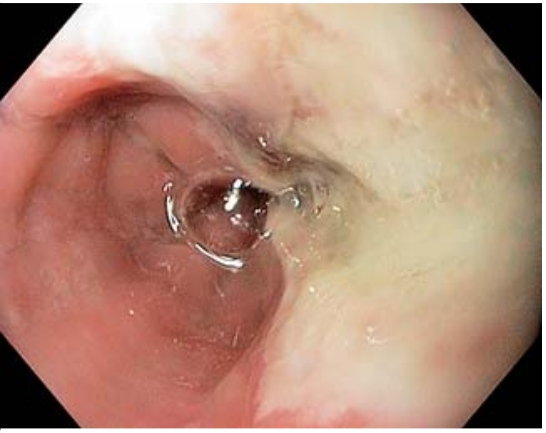

- Fig. 3 Inspection of the perforation wound after 36 hours with intraluminal endoscopic negative pressure therapy using the NGT-like single-lumen openpore film drain.

9 days after the perforation. The defect healed completely with a small scar without stenosis ( $\mathbf{F i g} .5$ ). Endoscopically, an esophageal trachealization was noticeable. The biopsy verified eosinophilic esophagitis. Therapy was initiated according to the guidelines.

For the initial emergency therapy of an esophageal perforation, the very easyto-use single-lumen open-pore film drain nasogastric tube was suitable. Intraluminal negative pressure application resulted in an immediate stop of extraluminal contamination. The esophagus was decompressed, the lumen collapsed, and secretions were drained. It is essential to check the inner wound and change the drain at regular intervals $[1,4,5]$.

Endoscopy_UCTN_Code_CPL_1AH_2AG

\section{Acknowledgments}

We would like to thank the nursing staff of the interdisciplinary endoscopic unit of Marienkrankenhaus Hamburg for their excellent technical assistance. We thank the Department of Diagnostic and Interventional Radiology of Marienkrankenhaus Hamburg for providing the radiological images.

\section{Competing interests}

Gunnar Loske is consultant of Lohmann \& Rauscher GmbH \& Co. KG. Ernst Scharsack and Olaf Gobrecht declare no conflict of interest.

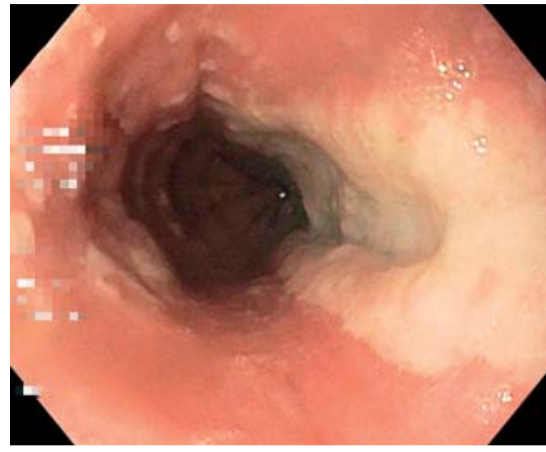

Fig. 4 Perforation wound after 4 days of intraluminal endoscopic negative pressure therapy. Therapy was terminated and nutrition started with a liquid diet.

The authors

\section{Gunnar Loske ${ }^{1}{ }^{\oplus}$ Ernst Scharsack ${ }^{1}$, Olaf}

\section{Gobrecht ${ }^{2}$}

1 Department for General, Abdominal, Thoracic and Vascular Surgery, Katholisches Marienkrankenhaus Hamburg gGmbH, Hamburg, Germany

2 Department for Medical Oncology and Hematology, Gastroenterology and Infectious Diseases, Katholisches Marienkrankenhaus Hamburg gGmbH, Hamburg, Germany

\section{Corresponding author}

\section{Gunnar Loske, MD}

Katholisches Marienkrankenhaus Hamburg $\mathrm{gGmbH}$, Department for General,

Abdominal, Thoracic and Vascular Surgery, Alfredstrasse 9, 22087 Hamburg, Germany Fax: +49-40-2546-1400

loske.chir@marienkrankenhaus.org

\section{References}

[1] Loske G, Schorsch T, Müller C. Intraluminal and intracavitary vacuum therapy for esophageal leakage: a new endoscopic minimally invasive approach. Endoscopy 2011; 43: 540-544

[2] Loske G, Müller CT. Tips and tricks for endoscopic negative pressure therapy. Chirurg 2019; 90: 7-14

[3] Loske G, Schorsch T, Rucktaeschel F et al. Open-pore film drainage (OFD): a new multipurpose tool for endoscopic negative pressure therapy (ENPT). Endosc Int Open 2018; 6: E865-E871

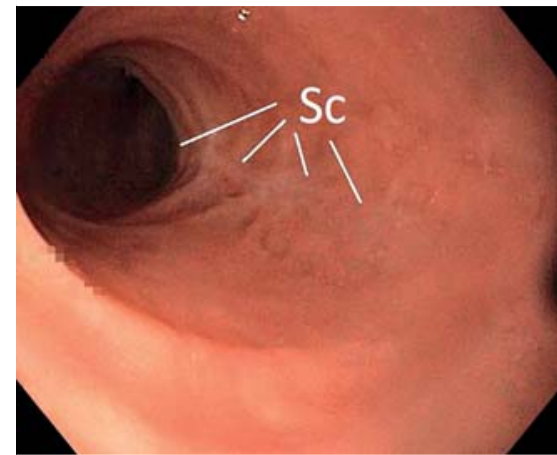

- Fig. 5 Follow-up 2 months after the long spontaneous perforation of the distal esophagus. Only a small scar was found, no stenosis. Sc, scar.

[4] Loske G, Schorsch T, Dahm C et al. Iatrogenic perforation of esophagus successfully treated with Endoscopic Vacuum Therapy (EVT). Endosc Int Open 2015; 3: E547-E551

[5] Wichmann D, Stüker D, Schempf U et al. Endoscopic negative pressure therapy with open-pore film drainage and open-pore polyurethane sponge drainage for iatrogenic perforation of the esophagus. Endoscopy 2020; 52: 377-382

Bibliography

Endoscopy 2022; 54: E247-E248

DOI 10.1055/a-1493-1805

ISSN 0013-726X

published online 8.6.2021

(c) 2021. Thieme. All rights reserved.

Georg Thieme Verlag KG, Rüdigerstraße 14, 70469 Stuttgart, Germany

\section{ENDOSCOPY E-VIDEOS}

https://eref.thieme.de/e-videos

口回回 Endoscopy E-Videos is an 留部 回辞: reporting on interesting cases and new techniques in gastroenterological endoscopy. All papers include a high quality video and all contributions are freely accessible online. Processing charges apply (currently EUR 375), discounts and wavers acc. to HINARI are available.

This section has its own submission website at

https://mc.manuscriptcentral.com/e-videos 